\title{
Challenges in retrieving stratospheric aerosol extinction and particle size from ground-based RMR-LIDAR observations
}

\author{
Jacob Zalach $^{1}$, Christian von Savigny ${ }^{1}$, Arvid Langenbach ${ }^{2}$, Gerd Baumgarten ${ }^{2}$, \\ Franz-Josef Lübken ${ }^{2}$, and Adam Bourassa ${ }^{3}$ \\ ${ }^{1}$ Institute of Physics, Greifswald University, Felix-Hausdorff-Str. 6, 17489 Greifswald, Germany \\ ${ }^{2}$ Leibniz-Institute of Atmospheric Physics, Schlossstr. 6, 18225 Kühlungsborn, Germany \\ ${ }^{3}$ University of Saskatchewan, 116 Science Place, Saskatoon, SK S7N 5E2, Canada \\ Correspondence to: J. Zalach (zalachj@uni-greifswald.de)
}

\begin{abstract}
We report on the retrieval of stratospheric aerosol particle size and extinction coefficient profiles from multi-color backscatter measurements with the Rayleigh-Mie-Raman lidar operated at the Arctic Lidar Observatory for Middle Atmosphere Research (ALOMAR) in northern Norway. The retrievals are based on a two-step approach. In a first step the median radius of an assumed lognormal particle size distribution with fixed width is retrieved based on the color ratio formed from the measured backscatter ratios at wavelenghts of $1064 \mathrm{~nm}$ and $532 \mathrm{~nm}$. An intrinsic ambiguity of the retrieved aerosol size information is discussed. In a second step, this particle size information is used to convert the measured lidar backscatter ratio to aerosol extinction coefficients. The retrieval is currently based on monthly-averaged lidar measurements covering the period from the year 2000 to present. A sensitivity study is presented that allows establishing an error budged for the aerosol retrievals. Assuming a log-normal aerosol particle size distribution with a geometric width of $S=1.3$, median radii on the order of $100 \mathrm{~nm}$ are retrieved. The median radii are found to generally decrease with increasing altitude. The retrieved aerosol extinction profiles are compared to observations with various current and past satellite instruments.
\end{abstract}

\section{Introduction}

\subsection{Importance of stratospheric aerosols}

Stratospheric aerosols are of crucial importance for various physical and chemical processes in the Earth's atmosphere. According to the current understanding, the main component of stratospheric aerosols consists of sub-micron particles made of $\mathrm{H}_{2} \mathrm{SO}_{4}$ and $\mathrm{H}_{2} \mathrm{O}$. This stratospheric sulfate aerosol 
layer is thought to be maintained under volcanically quiescent conditions by a continuous influx of OCS from the troposphere (Crutzen, 1976). Volcanic eruptions may lead to stratospheric injections of sulfur compounds, which can be photochemically converted to $\mathrm{H}_{2} \mathrm{SO}_{4}$ and contribute to the formation and growth of sulfate aerosol particles. Stratospheric sulfate aerosols scatter incoming solar radiation and also absorb and re-emit terrestrial thermal radiation. The net effect of an enhanced anthropogenically enhanced stratospheric halogen loading, an increase of the aerosol surface area leads to a net catalytic destruction of stratospheric $\mathrm{O}_{3}$. This effect will be reversed, once the stratospheric halogen load has returned to background levels (e.g. Tie and Brasseur, 1995). In polar regions stratospheric aerosols provide condensation nuclei for polar stratospheric clouds (PSC) which facilitate heterogeneous chemical reactions that lead to chlorine activation, which in turn leads to catalytic ozone loss.

\subsection{Novel aspects of the utilised approach}

Up to now long-term lidar observations of stratospheric aerosols were essentially limited to midlatitudes. The atmosphere in the Arctic region is much less explored and exhibits characteristic variations of its aerosol load as well as its thermal, dynamic and chemical properties. In the current study observations of stratospheric aerosols obtained by measurements with the Rayleigh-MieRaman-lidar (RMR-lidar) at the ALOMAR (Arctic Lidar Observatory for Atmospheric Research) station (von Zahn et al., 2000) located at $16.0^{\circ} \mathrm{E}, 69.3^{\circ} \mathrm{N}$ are analysed.

The number of experimental studies on the size of stratospheric sulfate aerosols is quite limited and the published aerosol sizes cover quite a large range of values, even under background aerosol conditions. A major advantage of this new method is that the lidar ratio does not have to be assumed, but is calculated from the measurements themselves. For most other lidar studies on stratospheric aerosols the value of the lidar ratio is determined based on a priori assumptions of the aerosol particle size distribution. In addition, the lidar ratio is usually assumed to be independent of altitude, which is generally not true.

To our best knowledge, the approach employed here - i.e. the retrieval of aerosol particle size information in a first step, followed by calculating extinction coefficients - has not yet been applied to lidar measurements of stratospheric sulfate aerosols. A similar approach, however, has been employed by Blum et al. (2006) and Jumelet et al. (2008) for investigating polar stratospheric clouds (PSCs).

\subsection{Outline}

The paper is structured as follows. Section 2 provides a brief description of the lidar system whose measurements are used in the present study. In section 3 we describe the steps of the retrieval ap- 
proach employed to, first, obtain information on the aerosol particle size and, second, to calculate the lidar ratio and retrieve the aerosol extinction coefficient and number density profile. The retrieval errors are discussed in section 4 and the inferred aerosol extinction coefficient profiles are compared with satellite-borne occultation and limb-scatter measurements in section 5. Conclusions are presented in the final section 6 .

\section{The ALOMAR Rayleigh-Mie-Raman (RMR) lidar}

The RMR lidar is described in von Zahn et al. (2000) and the basic data processing steps are found in Brand et al. (2019). It has the ability to measure elastically scattered photons at its principal wavelengths of $1064 \mathrm{~nm}, 532 \mathrm{~nm}$ and $355 \mathrm{~nm}$, which are scattered by molecules and aerosol particles, as well as Raman-scattered photons at $387 \mathrm{~nm}$ and $608 \mathrm{~nm}$, which are scattered by molecules only. This feature allows to calculate backscatter ratios for the principal wavelengths given above.

The backscatter ratio for a given wavelength is the ratio of the detected signal originating from scattering processes on aerosol particles (Mie-scattering) and air molecules (Rayleigh-scattering) normalized by the contribution of molecular scattering only (see eq. (3)). Therefore it contains information about the aerosol load in the scattering air volume. These backscatter ratios will be used here for the retrieval and further explained in the next section.

\section{Retrieval approach}

The main goal of this study is to describe an approach for the retrieval of vertical extinction and particle size profiles of stratospheric sulfate aerosol from ground-based multi-color lidar observations. Since backscatter ratios at three wavelengths are available, a method to simultaneously infer the log-normal distribution width and median radius from two color ratios could in principle be employed as described by von Cossart et al. (1999) and Baumgarten et al. (2007), who applied it to lidar measurements of noctilucent clouds (NLCs). This method is based on the exploitation of two color ratios determined from the lidar measurements at the three available wavelengths $(355 \mathrm{~nm}, 532 \mathrm{~nm}$ and $1064 \mathrm{~nm}$ ). The method works well for the relatively small NLC particles which reach radii of up to about $100 \mathrm{~nm}$, but is not generally applicable to stratospheric aerosol particles, whose median radii may well exceed $100 \mathrm{~nm}$. Therefore, this approach is not utilized here. Instead, a simplified approach, as outlined by Yue and Deepak (1983), is necessary which sets one of the two distribution parameters to a constant value (here, the distribution width) and retrieves the remaining one (the median radius).

The retrieval is performed in two steps. First, aerosol particle size is found by comparing the measured and modelled color ratio of the backscatter ratio profiles at two different wavelengths.

This can be done because the color ratio for the wavelengths used depends on the median radius of the assumed log-normal size distribution. Second, the inferred particle size is employed to calcu- 


\section{$91 \quad 3.1 \quad$ Retrieval assumptions}

Some general assumptions were made prior to the retrieval. Backscatter ratios at $1064 \mathrm{~nm}$ and $532 \mathrm{~nm}$ were chosen for the retrieval instead of $355 \mathrm{~nm}$, because measurements at this wavelength essentially serve as a measure for Rayleigh scattering (Brand et al., 2019). The aerosol is assumed to consist of $75 \%$ sulfuric acid $\left(\mathrm{H}_{2} \mathrm{SO}_{4}\right)$ and $25 \%$ water which defines its refractive index. For the assumed aerosol composition the real part of the refractive index is roughly 1.43 at the wavelength of $532 \mathrm{~nm}$ and 1.42 at $1064 \mathrm{~nm}$ (Palmer and Williams, 1975). Aerosol absorption turned out to have only negligible influence on the retrieval, therefore the imaginary part of the refractive index was set to zero. The particle size distribution (PSD) is assumed to be log-normal,

$$
\frac{d N_{A}}{d r}=\frac{N_{A}}{\sqrt{2 \pi} \ln (S) r_{m}} \cdot \exp \left(-\frac{\left(\ln (r)-\ln \left(r_{m}\right)\right)^{2}}{2 \ln ^{2}(S)}\right)
$$

100 with $N_{A}$ as the number density of the aerosol particles, $S$ the geometric standard deviation (distri-

In the first step the particle size is retrieved, which is a necessary requirement for further computations. The lidar backscatter ratio $R\left(z, r_{m}, \lambda\right)$ at altitude $z$ and wavelength $\lambda$ is given by

$$
R\left(z, r_{m}, \lambda\right)=\frac{\beta_{\text {Mie }}\left(z, r_{m}, \lambda\right)+\beta_{\text {Ray }}(z, \lambda)}{\beta_{\text {Ray }}(z, \lambda)}
$$

110 which can be simplified to

$$
R\left(z, r_{m}, \lambda\right)=\frac{\beta_{\text {Mie }}\left(z, r_{m}, \lambda\right)}{\beta_{\text {Ray }}(z, \lambda)}+1
$$

111 with the aerosol and Rayleigh volume backscatter coefficients $\beta_{M i e}\left(z, r_{m}, \lambda\right)$ and $\beta_{\text {Ray }}(z, \lambda)$ which 112 are defined as

$$
\beta_{M i e}\left(z, r_{m}, \lambda\right)=k_{M i e}^{s c a}\left(z, r_{m}, \lambda\right) \cdot P_{M i e}\left(\Theta, r_{m}, \lambda\right)
$$




$$
\beta_{\text {Ray }}(z, \lambda)=k_{M i e}^{s c a}(z, \lambda) \cdot P_{\text {Ray }}(\Theta)
$$

114 Here, $k_{M i e / R a y}^{s c a}$ denotes scattering coefficients, $P_{\text {Mie/Ray }}$ the phase functions for Mie and Rayleigh scattering, respectively and $\Theta=180^{\circ}$ is the scattering angle. The scattering coefficients $k_{\text {Mie/Ray }}^{s c a}$ depend on air/aerosol densities and the respective scattering cross sections. In the case of Mie scattering on aerosol particles eq. (4) can be expanded to include both values giving

$$
\beta_{M i e}\left(z, r_{m}, \lambda\right)=N_{A}(z) \cdot \sigma_{M i e}\left(z, r_{m}, \lambda\right) \cdot P_{M i e}\left(\Theta, r_{m}, \lambda\right)
$$

118 119 true

$$
\beta_{\text {Ray }}(z, \lambda)=N(z) \cdot \sigma_{\text {Ray }}(z, \lambda) \cdot P_{\text {Ray }}(\Theta) .
$$

All values used are summarized and explained in Table 1.

\begin{tabular}{ll}
\hline$\Theta$ & Scattering angle $(\Theta=\pi$ for lidar observations) \\
$R$ & Backscatter ratio (dimensionless) \\
$k_{\text {Mie }}^{\text {sca }}$ & Mie scattering coefficient $\left[\mathrm{km}^{-1}\right]$ \\
$k_{\text {Ray }}^{\text {sca }}$ & Rayleigh scattering coefficient $\left[\mathrm{km}^{-1}\right]$ \\
$P_{\text {Mie }}(\Theta, \lambda)$ & Mie scattering phase function $\left[\mathrm{sr}^{-1}\right]$ \\
$P_{\text {Ray }}(\Theta)$ & Rayleigh scattering phase function $\left[\mathrm{sr}^{-1}\right]$ \\
$\beta_{\text {Mie }}$ & Mie volume scattering coefficient $\left[\mathrm{km}^{-1} \mathrm{sr}^{-1}\right]$ \\
$\beta_{\text {Ray }}$ & Rayleigh volume scattering coefficient $\left[\mathrm{km}^{-1} \mathrm{sr}^{-1}\right]$ \\
$N_{A}(z)$ & Aerosol particle density $\left[\mathrm{m}^{-3}\right]$ \\
$N(z)$ & Air (molecule) density $\left[\mathrm{m}^{-3}\right]$ \\
$\sigma_{M i e}(z, \lambda)$ & Mie scattering cross section $\left[\mathrm{m}^{-2}\right]$ \\
$\sigma_{\text {Ray }}(z, \lambda)$ & Rayleigh scattering cross section $\left[\mathrm{m}^{-2}\right]$ \\
\hline \hline
\end{tabular}

Table 1. Compilation of used variables and terminology.

120

$$
\begin{aligned}
C\left(z, r_{m}, \lambda_{1}, \lambda_{2}\right) & =\frac{R\left(z, r_{m}, \lambda_{1}\right)-1}{R\left(z, r_{m}, \lambda_{2}\right)-1} \\
& =\frac{\beta_{\text {Mie }}\left(z, r_{m}, \lambda_{1}\right)}{\beta_{\text {Mie }}\left(z, r_{m}, \lambda_{2}\right)} \cdot \frac{\beta_{\text {Ray }}\left(z, \lambda_{2}\right)}{\beta_{\text {Ray }}\left(z, \lambda_{1}\right)}
\end{aligned}
$$

with $\lambda_{1}=1064 \mathrm{~nm}$ and $\lambda_{2}=532 \mathrm{~nm}$. Considering the last factor of eq. (8) - describing the 
present in both the numerator and denominator. Considering eq. (7) this is obviously the case for the Rayleigh scattering phase function $P_{R a y}(\Theta)$ as well as the vertical air density profile $N(z)$. Thus, the contribution of Rayleigh scattering at the two wavelengths in eq. (8) is reduced to a ratio of Rayleigh scattering cross sections (Bucholtz, 1995):

$$
\sigma_{R a y}(\lambda)=\frac{24 \pi^{3}}{\lambda^{4} N_{0}^{2}} \frac{\left(n_{0}(\lambda)^{2}-1\right)^{2}}{\left(n_{0}(\lambda)^{2}+2\right)^{2}}\left(\frac{6+3 \gamma(\lambda)}{6-7 \gamma(\lambda)}\right) .
$$

Here, $N_{0}$ denotes the number density of air for standard conditions, $n_{0}(\lambda)$ is the refractive index for the given wavelength, also for standard conditions, with $n_{0}(532 \mathrm{~nm})=1.0002782$, and $\gamma(\lambda)$ is the depolarisation factor of air. Finally, the color ratio from eq. (8) becomes

$$
C\left(z, r_{m}, \lambda_{1}, \lambda_{2}\right)=\frac{\beta_{\text {Mie }}\left(z, r_{m}, \lambda_{1}\right)}{\beta_{\text {Mie }}\left(z, r_{m}, \lambda_{2}\right)} \cdot\left(\frac{\sigma_{\text {Ray }}\left(\lambda_{1}\right)}{\sigma_{\text {Ray }}\left(\lambda_{2}\right)}\right)^{-1} \cdot
$$

Beside the dependence on altitude and wavelength the color ratio in eq. (10) depends only on the assumed PSD and the aerosol refractive index which implicitly affects the aerosol backscatter coefficient.

For the forward model a log-normal PSD was assumed (eq. (1)). As already mentioned, our retrieval approach uses a single color ratio from measurements at $1064 \mathrm{~nm}$ and $532 \mathrm{~nm}$, so only a single particle size parameter can be retrieved, e.g., the median radius of an assumed PSD with fixed width. In this study, the standard deviation of the PSD is set to a fixed value of $S=1.3$ and the median radius $r_{m}$ is retrieved using eq. (10).

The Mie-scattering cross sections $\sigma_{M i e}\left(z, r_{m}, \lambda\right)$ and Mie phase functions $P_{M i e}\left(\Theta, \lambda, r_{m}\right)$ used in the forward model (eq. (10) and (4)) are calculated using the IDL Mie scattering routines provided by the University of Oxford (Mie scattering routines, 2018).

Finally, by evaluating eq. (10) the color ratio is obtained as a function of radius $r_{m}$ as shown in Figure 1 for the wavelengths $1064 \mathrm{~nm}$ and $532 \mathrm{~nm}$ and for different distribution widths. Then, color ratios obtained from measured data are directly compared with the computed curve. This comparison allows to identify those radii for which the curve has the same value as the measurement.

\subsection{Radius ambiguity}

The proper radius assignment described above requires further explanations as it is not necessarily unique. As seen in Figure 1 most of the measured color ratio values can be found at several points on the color ratio-radius curve. This behaviour depends on the assumed distribution width. To give an example, we assume a measured color ratio value of 3 as marked in the Figure (dashed horizontal line) and a distribution width of $S=1.1$ (black curve). The color ratio function gives the same value for median radii of roughly $100 \mathrm{~nm}, 270 \mathrm{~nm}$ and $310 \mathrm{~nm}$. With respect to its local extrema the curve can be divided into intervals which can be labeled as branch 1, branch 2, branch 3 and so on. For example, the first branch would extend from the first local minimal value at $\mathrm{r}=0 \mathrm{~nm}$ to $\mathrm{r}=146 \mathrm{~nm}$, whereas branch 3 would range from roughly $r=290 \mathrm{~nm}$ to $\mathrm{r}=400 \mathrm{~nm}$. 


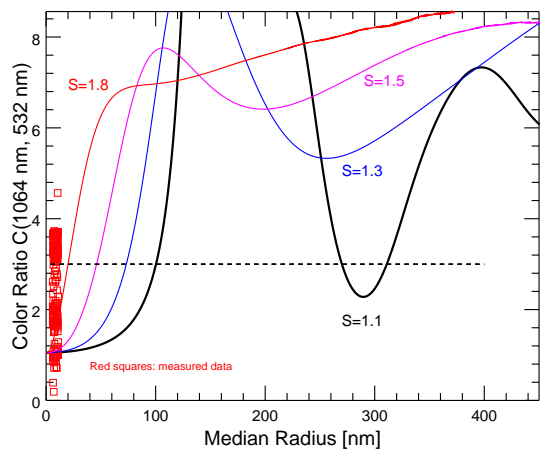

Fig. 1. Radius dependence of the color ratio $C$ for $\lambda_{1}=1064 \mathrm{~nm}$ and $\lambda_{2}=532 \mathrm{~nm}$ (see eq. (8)) calculated using a Mie scattering code for different distribution widths $S$ (solid lines). As an example, color ratios from measured monthly averaged backscatter profiles of March 2013 are shown as open red squares on the left.

The division into separate branches is important to illustrate the ambiguity of the radius retrieval employing this method. Since the aerosol radius is not known in advance, the correct branch for the retrieval has to be chosen using physical considerations.

First, it should be noted that by increasing the assumed distribution width the computed color ratio curve changes its shape. This change has two consequences - branch 1 shifts toward smaller radii and the eye-catching minimum at roughly $290 \mathrm{~nm}$ for $S=1.1$ rises fast. This rise leaves an ever growing portion of measured data points below its minimal value, hence without a possibility to assign a radius using other branches than branch 1 . Above a distribution width of around $S=1.75$ any ambiguity vanishes since no minima are found on the computed color ratio curve. A subdivision into several branches is then not possible anymore. Therefore only branch 1 allows for a radius retrieval which covers the whole altitude range for all possible distribution widths. In this context it is worth to point out that several studies report distribution widths well exceeding 1.4 (McLinden et al., 1999; Bourassa et al., 2008; Ugolnikov et al., 2018). Some studies report $S=1.1$ and even lower (Bingen et al., 2004a), but we think that these values are not compatible with our measurements: for aerosol populations with a rather small particle size only a retrieval based on branch 1 gives plausible results since it allows for a smooth transition between very small radii and the maximal radius. Retrievals based on other branches lead to a radius distribution with a very high minimal value of several hundred nanometer without any transition to smaller values along the vertical profile. Figure 2 shows the issue. For color ratios of $C<2.4$ (see Figure 1), branch 3 reproduces the measured color ratio only for distribution widths smaller than $S=1.1$. In this cases the particle size would be larger than $290 \mathrm{~nm}$. We see two reasons for excluding branch 3: Very small distribution withs with $S \leq 1.1$ are not compatible with our data set as we use monthly mean lidar data. The variability of the 


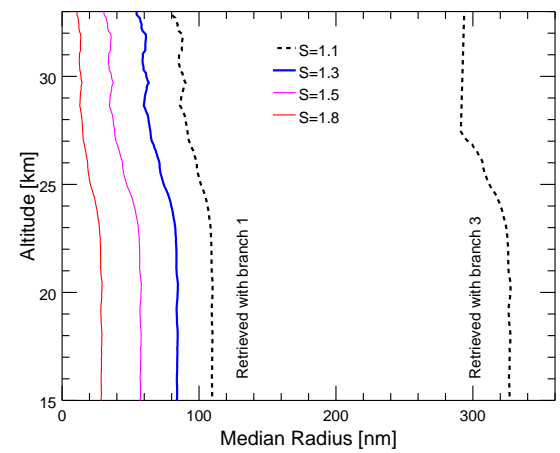

Fig. 2. Retrieved median radius profiles based on branch 1 (curves on the left) and branch 3 (black curve on the right). The branch 1 retrievals are shown for different $S$ to illustrate its influence on the radius retrieval. For $S<1.1$ a radius assignment using branch 3 exists for the altitude range up to $30 \mathrm{~km}$ as shown in the rightmost profile (for $S=1.1$ ). Shown are monthly mean profiles for March 2013.

background conditions throughout the month should lead to distribution widths $S \geq 1$.1. Secondly, the absence of median radii below some $100 \mathrm{~nm}$ does not characterise a physically plausible aerosol size profile.

The other radius profiles shown in Figure 2 were obtained by evaluating branch 1 of the color ratio function for different distribution widths. In the shown example the radius retrieval evaluating branch 2 only was discarded because the resulting radius profile is inverted with a steady growing median radii with altitude. So branch 2 leads to obviously implausible profiles.

The other branches of the color ratio curve become important, if the particle size distribution extends to median radii beyond the local extrema of the curve (Figure 1). This may happen, for example, after volcanic eruptions (Deshler, 2008). In such cases the retrieval using single branches of the color ratio function would recover only parts of the whole profile. This feature is a weak point of the method employed here and reduces its robust application to aerosol populations with radii below roughly $150 \mathrm{~nm}$. However, such cases like volcanic eruptions are usually identified by sudden enhancements of the backscatter ratio at limited altitudes and may be removed from further processing (Brand et al., 2019).

\subsection{Derivation of extinction profiles}

Once the radius is determined the extinction profile is calculated. To compute the desired extinction profiles eq. (3) can be solved for

$$
k_{M i e}^{s c a}\left(z, r_{m}, \lambda\right)=\frac{k_{R a y}^{s c a}(z, \lambda) \cdot P_{R a y}(\Theta)}{P_{M i e}\left(\Theta, r_{m}, \lambda\right)} \cdot\left(R\left(z, r_{m}, \lambda\right)-1\right) .
$$




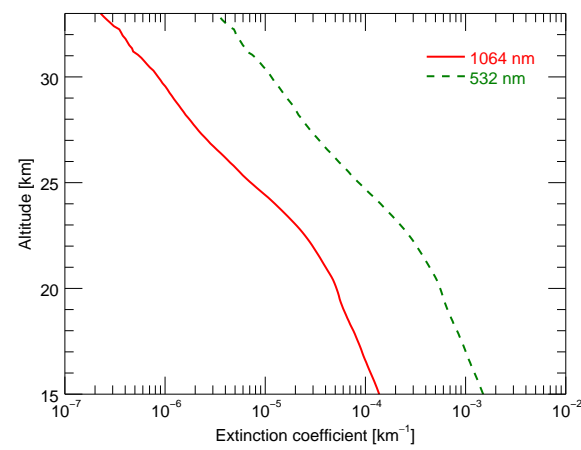

Fig. 3. Monthly mean of extinction coefficient profiles for March 2013 retrieved for an assumed distribution width of $S=1.3$

All quantities on the right hand side of this equation are either measured, like the backscatter ratio $R(z, \lambda)$, or can be retrieved. The air density is calculated from monthly means (of daily means) of temperature and pressure profiles obtained from ERA-Interim data sets provided by the European Centre for Medium-range Weather Forecast (ECMWF Database, 2018). With those ingredients inserted into eq. (11) extinction profiles are computed for the two wavelengths initially used to derive the particle size distribution. Figure 3 shows as an example the aerosol extinction profiles at $532 \mathrm{~nm}$ and $1064 \mathrm{~nm}$ based on monthly averaged lidar measurements for March 2013 and assuming a distribution width of $S=1.3$.

The calculation in eq. (11) makes use of the reciprocal value of the Mie phase function for a scattering angle of $180^{\circ}$, the so called lidar ratio $\Lambda$, which is defined as the ratio of the extinction and backscatter coefficient

$$
\Lambda\left(r_{m}, \lambda\right)=\frac{k_{s c a}\left(r_{m}, \lambda\right)}{\beta_{\text {Mie }}\left(\Theta, r_{m}, \lambda\right)}=\frac{1}{P_{M i e}\left(\Theta, r_{m}, \lambda\right)} .
$$

The possibility to compute the Mie phase function, and therefore the lidar ratio, from the retrieved median radius is an advantageous feature of this method.

In cases where a computation like in our approach is not possible usually a constant lidar ratio with values around $50 \mathrm{sr}$ for $532 \mathrm{~nm}$ is often assumed, e.g. Khaykin et al. (2017). To compute the extinction coefficient this way, eq. (12) is used leading to

$$
k_{\text {Mie }}^{s c a}(z, \lambda)=\Lambda\left(r_{m}, \lambda\right) \cdot \beta_{M i e}(\Theta, z, \lambda) .
$$

213 This approach constitutes the only way to estimate aerosol extinction coefficients if lidar measure214 ments are available only at a single wavelength. However, assuming a constant lidar ratio does not 


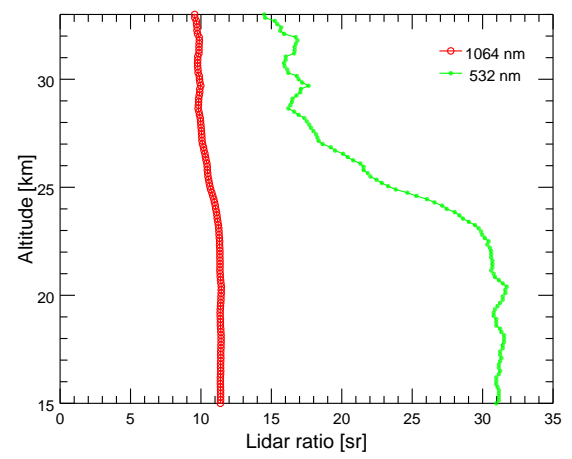

Fig. 4. Dependence of the lidar ratio on median radius for an assumed distribution width of $\mathrm{S}=1.3$.

account for its dependence on the radius, and therefore on its implicit dependence on altitude. The lidar ratio profile in Figure 4 shows that the assumption of a constant lidar ratio can be an good approximation for a certain altitude range, here between 15 and $23 \mathrm{~km}$. But for altitudes above $23 \mathrm{~km}$ the lidar ratio changes significantly, therefore leading to inevitable errors if its value is assumed constant. To give an example, if our retrieval is done with a constant lidar ratio of $30 \mathrm{sr}$ for $532 \mathrm{~nm}-$ this value is taken from Figure 4 - the resulting extinction coefficient profile agrees very well with our approach desctibed in this work for altitudes below $23 \mathrm{~km}$ but the deviation rises to roughly $80 \%$ at $30 \mathrm{~km}$. This deviation would be bigger if a higher value (of the constant lidar ratio) would be chosen, e.g. roughly $300 \%$ for $50 \mathrm{sr}$.

\subsection{Particle number density estimation}

Together with the extinction profiles retrieved in the previous section all information is available to estimate the aerosol number density $N_{A}$ utilising the relationship between extinction coefficient, scattering cross section and particle number density. With the mean cross section of a given PSD

$$
\left\langle\sigma_{M i e}(z, \lambda)\right\rangle=\int_{0}^{\infty} \frac{d N_{A}\left(r, r_{m}(z), S\right)}{d r} \cdot \sigma_{M i e}\left(r, \lambda, n_{0}^{A}\right) d r,
$$

with $n_{0}^{A}$ as the refractive index of the aerosol, the particle density is given by

$$
N_{A}(z)=\frac{k_{M i e}^{s c a}(z, \lambda)}{\left\langle\sigma_{M i e}(z, \lambda)\right\rangle} .
$$

For both extinction profiles retrieved one step earlier (eq. (11)) density profiles are computed which, of course, are identical for the two wavelengths as can be seen in Figure 5. 


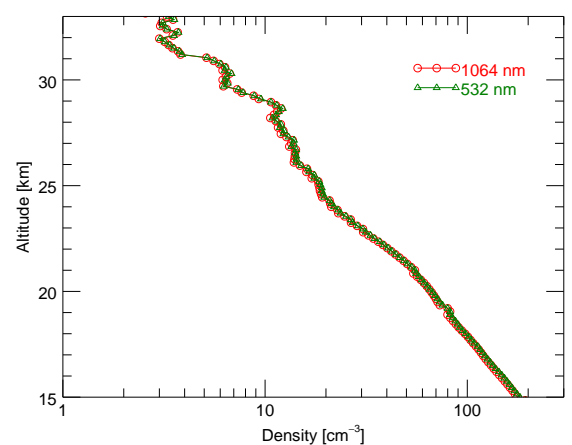

Fig. 5. Stratospheric aerosol particle density profiles obtained from the extinction coefficient profiles at $532 \mathrm{~nm}$ and $1064 \mathrm{~nm}$ shown in Figure 3. Monthly mean for March 2013 with an assumed distribution width of $S=1.3$.

\section{Error estimation}

A key point of the retrieval approach employed here is a correct radius determination, since all inferred quantities depend on it. Therefore, the input parameters, i.e. the assumed distribution width (S) and the aerosol refractive index $\left(\mathrm{n}_{0}\right)$, are carefully chosen and their impact on the result - together with impact of measurement errors - is assessed in order to obtain a measure of the reliability of the results.

In order to determine the impact of every parameter on the resulting aerosol particle size and extinction coefficients, the retrieval was performed with consecutively perturbed parameter values used in the forward model. The following perturbations from nominal values were assumed: a temperature perturbation of $\pm 1 \mathrm{~K}$, a pressure perturbation of $\pm 1 \%$, a refractive index perturbation of 0.04 (which corresponds roughly to a $20 \%$ change of the $\mathrm{H}_{2} \mathrm{SO}_{4}$ concentration) and finally a distribution width perturbation of $\Delta S= \pm 0.1$ and $\Delta S= \pm 0.2$, respectively.

For the first step of the retrieval procedure, i.e. the radius determination, the error contribution of each parameter is shown in Figure 6. Since the radius is derived from the computed color ratio it does not depend on temperature and pressure because those values cancel out (see eq. (10)). The most significant impact on the radius determination comes from an incorrect assumption on the distribution width. A difference of $\Delta S= \pm 0.2$ leads to relative error of slightly below $\Delta r / r=\mp 40 \%$.

If the assumed distribution width is increasing, then the retrieved median radius is decreasing, and vice versa. If the single error contributions are simply added to a total error - separately for the two assumed deviations of the distribution width - an absolute error range can be assigned to the retrieved radius profile as shown in Figure 7. The contribution of every parameter variation to the total error of aerosol extinction coefficients is shown in Figure 8. Again, the dominant contribution 

big as in the case of the radius retrieval shown in Figure 6 because the impact on the Mie phase function - which is needed to compute the extinction coefficient (eq. (11)) - associated with a high/low bias in the distribution width $S$ is partly compensated by a low/high bias in the retrieved value of $r_{m}$. Therefore, the inferred extinction coefficients seem to be rather robust against variations of the distribution width as seen in Figure 9, which shows extinction coefficient profiles together with the total accumulated error. Like in Figure 7 two error ranges are given for the two assumed errors of the distribution width of $\Delta S= \pm 0.1$ and $\Delta S= \pm 0.2$, respectively.

261 Finally, we investigate the error of the number density in Figure 10. Due to its direct depen262 dency on the distribution width and radius (eq. (14) and (15)), this value is very sensitive to those 263 uncertainties giving rise to relatively large errors.

\section{Comparison with independent observations}

This section deals with two different aspects. In section 5.1 the retrieved radii of stratospheric sulfate

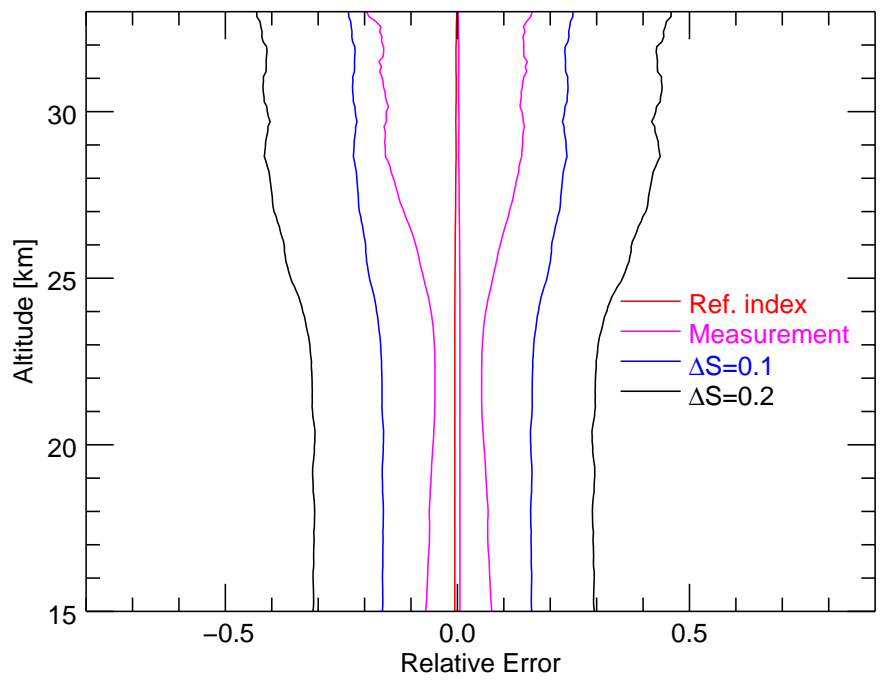

Fig. 6. Impact of measurement errors, distribution width and aerosol refractive index on the radius retrieval. 


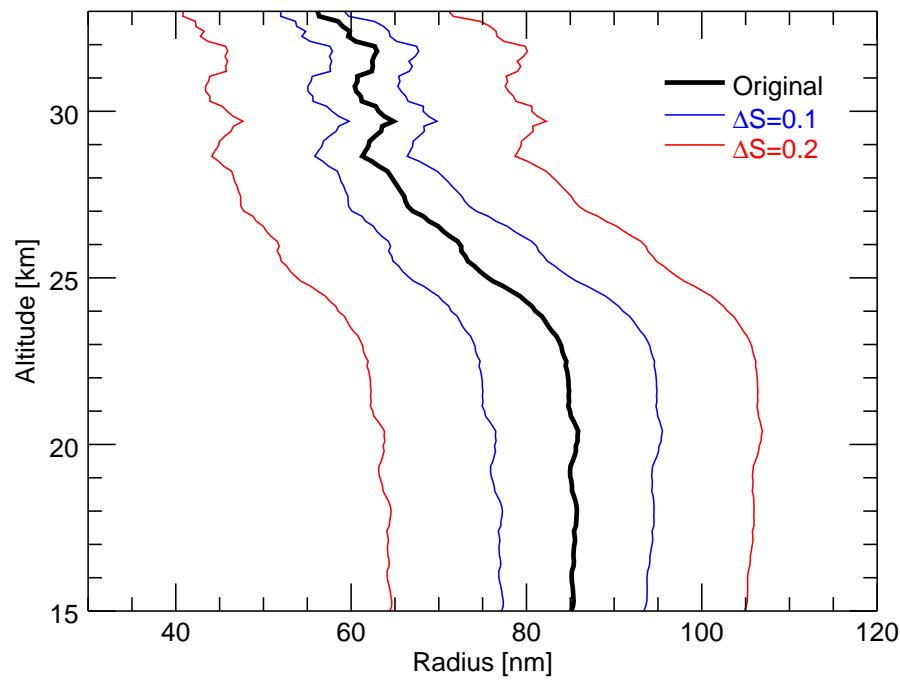

Fig. 7. Radius profile inferred with an assumed distribution width of $S=1.3$ (black curve). The error ranges are obtained by adding all single error contributions (Monthly mean for March 2013).

\subsection{Comparison of particle size retrievals}

The number of available studies on the size of stratospheric sulfate particles is rather limited. Here, we limit the considerations to qualitative comparisons of non-collocated measurements.

McLinden et al. (1999) employed polarized limb-radiance measurements with the CPFM (Composition and Photodissociative Flux Measurement) spectroradiometer operated on NASA's ER-2 high altitude aircraft during two field campaigns in April and May 1997. Both flights started in Fairbanks, Alaska $\left(65^{\circ} \mathrm{N}, 148^{\circ} \mathrm{W}\right)$ and covered the high latitude American sector. For the retrieval of aerosol particle size information CPFM limb scans at latitudes of $83^{\circ} \mathrm{N}$ and $75^{\circ} \mathrm{N}$, respectively were used. For their aerosol retrieval McLinden et al. (1999) assumed an altitude independent log-normal PSD which they claimed it to be representative of the aerosol at all heights in the lower stratosphere covered by the measurements. Median radii of $r_{m}=120 \pm 20 \mathrm{~nm}$ and $100 \pm 20 \mathrm{~nm}$ and logarithmic standard deviations of $0.44 \pm 0.04$ and $0.46 \pm 0.04$ were retrieved for the two flights. Converted to the geometric standard deviations, the width values are $S=1.55 \pm 0.06$ and $S=1.58 \pm 0.06$, respectively.

Bourassa et al. (2008) retrieved stratospheric aerosol particle size information from OSIRIS limbscatter measurements at $750 \mathrm{~nm}$ and $1530 \mathrm{~nm}$, also assuming a log-normal PSD. From a single limb- 


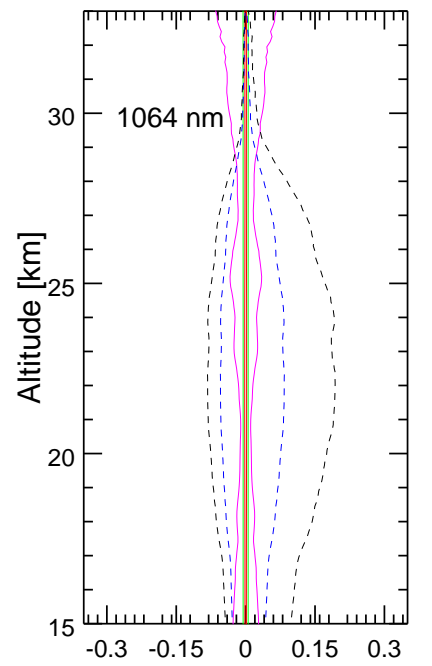

Rel. Error

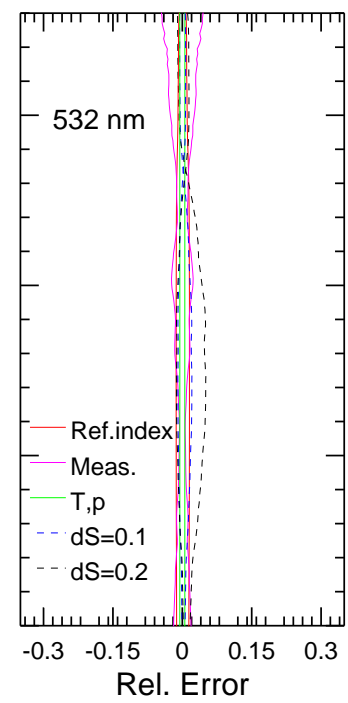

Fig. 8. Relative error of the extinction coefficient due to uncertainties in refraction index, temperature, distribution width and measurement error of monthly mean values for March 2013.

scan - assuming a geometric standard deviation of 1.6 - the authors retrieved a median (the article incorrectly states mode) radius, decreasing from about $100 \mathrm{~nm}$ at $21 \mathrm{~km}$ to about $30 \mathrm{~nm}$ at $30 \mathrm{~km}$ altitude. The analyzed limb scan was performed on January 5, 2004 at $-35.6^{\circ} \mathrm{S}$ latitude and $112.6^{\circ}$ longitude.

Ugolnikov et al. (2018) presented stratospheric aerosol particle size retrievals from ground-based multi-spectral twilight measurements carried out with an all-sky camera in central Russia $\left(55.2^{\circ} \mathrm{N}\right.$, $37.5^{\circ} \mathrm{E}$ ) in spring and summer 2016 , i.e. for volcanically relatively quiescent conditions. The authors assumed a log-normal PSD retrieved a mean aerosol radius of about $r_{m}=80 \mathrm{~nm}$ and a width of $S=1.5-1.6$

Bingen et al. (2004a); Bingen at al. (2004b) retrieved stratospheric aerosol particle size information from SAGE II solar occultation measurements for the period from 1985 to 2000 . The retrieved aerosol radii - it is unclear which radius is shown, because both the terms mode and median are used - are on the order of $200-350 \mathrm{~nm}$ at an altitude of $22.5 \mathrm{~km}$ in 1999, i.e. 8 years after the eruption of Mt. Pinatubo, when the stratospheric aerosol load was again close to background conditions. It is, however, important to mention that the retrieved PSDs are rather narrow, with $S \leq 1.1$.

Deshler (2008) retrieved stratospheric aerosol particle size from balloon-borne measurements done at Laramie (Wyoming, USA, $41^{\circ} \mathrm{N}, 105^{\circ} \mathrm{W}$ ). This analysis considered a bimodal size dis- 


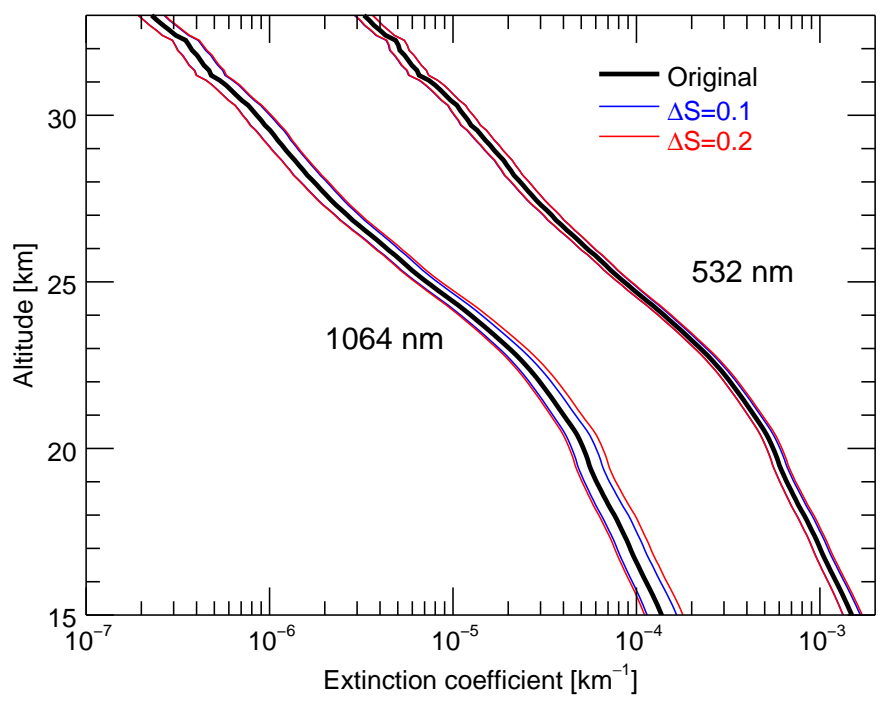

Fig. 9. Extinction coefficient profiles inferred with an assumed distribution width of $S=1.3$ with total error ranges of the two assumed deviations of the distribution width (Monthly mean for March 2013.)

tribution which may be present even at background aerosol conditions. Averaged profiles obtained between 1995 and 2003 without volcanic aerosol load from Pinatubo show an increase of the median radius of the main mode from roughly $45 \mathrm{~nm}$ at $16 \mathrm{~km}$ up to a maximum of $80 \mathrm{~nm}$ at $21 \mathrm{~km}$ with a distribution width of $S=1.37$. For the time period with volcanic aerosols a maximal median radius of the main mode is found to be around $180 \mathrm{~nm}$ with $\mathrm{S}=1.41$.

In summary, a majority of the limited number of studies on the size of stratospheric sulfate aerosols yields - under volcanically quiescent conditions - median radii on the order of about $100 \mathrm{~nm}$, in good overall agreement with the retrievals presented here. The exception are size retrievals based on multi-spectral solar occultation measurements with SAGE II (Bingen et al., 2003, 2004a; Bingen at al., 2004b) yielding mode (or median radii, this distinction was not made by the authors) of several hundred nm, even in the late 1990s, when the Pinatubo aerosol has already almost entirely disappeared. These discrepancies may in part be a consequence of different sensitivities to the aerosol particle population in combination with errors in the assumed PSD. 


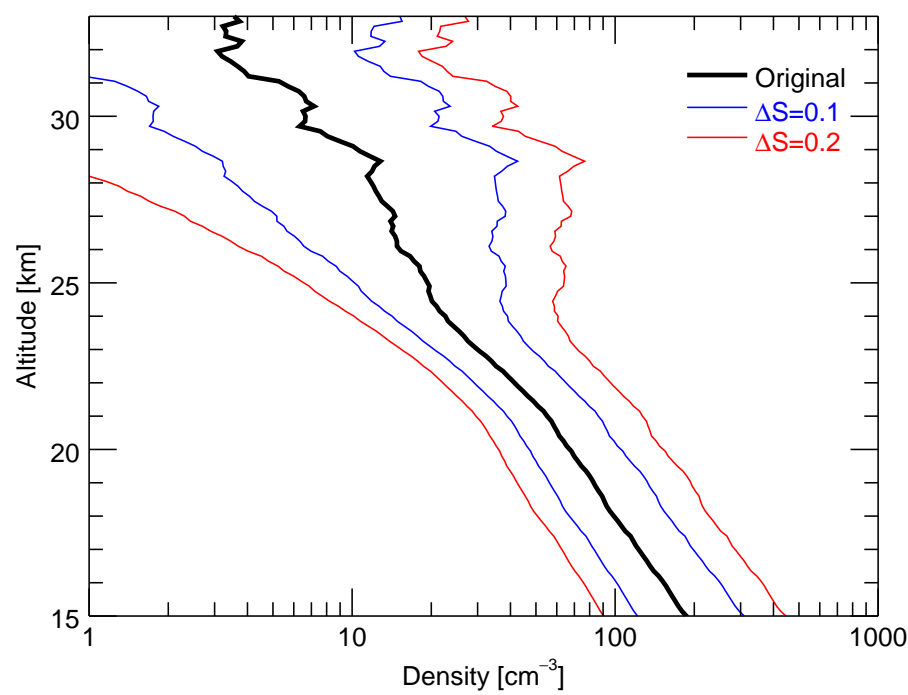

Fig. 10. Aerosol density profile inferred with an assumed distribution width of $S=1.3$ with total error ranges (Monthly mean for March 2013.)

\subsection{Comparison with satellite aerosol extinction observations}

In this section the extinction coefficient profiles retrieved from the measurements with the ALOMAR lidar are compared to aerosol extinction profiles retrieved from measurements with different satellite instruments. Specifically, we use observations from two instruments.

OSIRIS (Optical Spectrograph and InfraRed Imaging System) (Llewellyn et al., 2004) was launched in 2001 on-board the Swedish/Canadian/Finish/French Odin satellite (Murtagh et al., 2002). OSIRIS performs limb-scatter observations in the $280-800 \mathrm{~nm}$ spectral range, allowing to retrieve stratospheric aerosol extinction profiles (Bourassa et al., 2012). Aerosol extinction is provided at a wavelength of $750 \mathrm{~nm}$ (data version 5.07).

OMPS (Ozone Mapping Profiling Suite) was launched in 2012 on-board the Suomi-NPP (Suomi National Polar-orbiting Partnership) satellite and performs nadir and limb-scatter measurements (e.g. Jarros et al., 2016). Stratospheric aerosol extinction profiles are retrieved from limb-scatter measurements and are provided at a wavelength of $675 \mathrm{~nm}$ (data version 1) (DeLand et al., 2016).

The wavelengths, at which the aerosol extinction coefficients are provided, the measurement geometry and covered time span are summarized in table 2.

For comparison monthly mean and zonally averaged data for March 2013 in the latitude range 


\begin{tabular}{ccccc}
\hline Instrument & Satellite & Time span & Geometry & $\lambda[\mathrm{nm}]$ \\
\hline OSIRIS & Odin & $2001-2017$ & Limb-scatter & 750 \\
OMPS & Suomi-NPP & $2012-2017$ & Limb-scatter & 675 \\
\hline \hline
\end{tabular}

Table 2. Overview on the satellite data used for comparison.

$60^{\circ} \mathrm{N}-80^{\circ} \mathrm{N}$ was used. Measurements performed in March should not be influenced by polar stratospheric clouds which frequently appear during winter months. Prior to the comparison the extinction profiles measured at the two wavelengths $1064 \mathrm{~nm}$ and $532 \mathrm{~nm}$ have to be converted to the wavelengths for which the satellite data is provided. This conversion is done using the Ångström approach (Ångström, 1929)

$$
k_{i}\left(\lambda_{i}, z\right)=c(z) \cdot \lambda_{i}^{-\alpha(z)}
$$

with the Ångström exponent $\alpha(z)$ and $\lambda_{i}$ denoting the considered or desired wavelength. Since our retrieval provides extinction coefficients profiles at two wavelengths the Ångström exponent is obtained by

$$
\alpha(z)=\frac{\ln \left(k_{e x t}\left(z, \lambda_{2}\right)\right)-\ln \left(k_{e x t}\left(z, \lambda_{1}\right)\right)}{\ln \left(\lambda_{1}\right)-\ln \left(\lambda_{2}\right)} .
$$

A comparison between the satellite observations and the lidar extinction profiles converted to the corresponding satellite wavelength is shown in Figure 11.
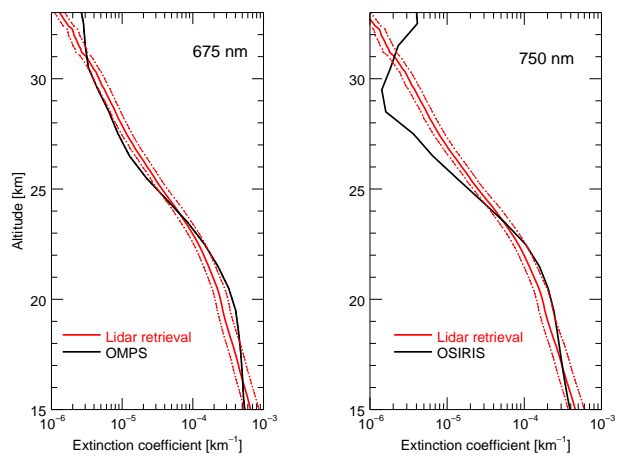

Fig. 11. Comparison of the re-scaled lidar extinction profiles with a maximal error range taken from Figure 9 $(\mathrm{S}=1.3)$ with profiles obtained from the OSIRIS and OMPS instruments for March 2013.

Relative deviations between the lidar extinction coefficient scaled to the wavelength used by the satellite and the satellite measurement are presented in Figure 12. The shapes of both profiles look very similar for altitudes below roughly $25 \mathrm{~km}$. Above this altitude however, the OSIRIS profile 


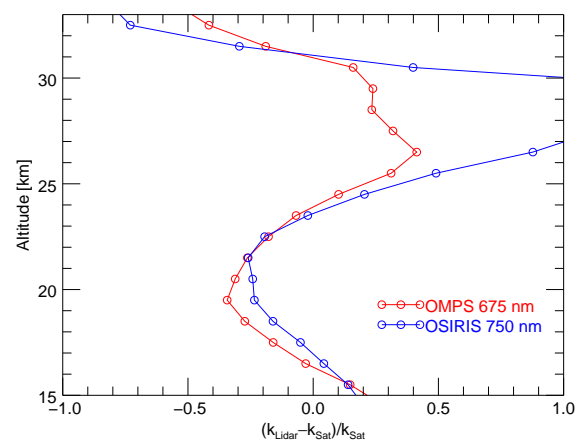

Fig. 12. Relative difference between the lidar extinction profile scaled to the satellite wavelength and satellite measurements for March 2013. The lidar extinction profiles were retrieved assuming with $\mathrm{S}=1.3$.

shows a pronounced dip-like structure. This behaviour is probably caused by a sporadically appearing low bias at high latitudes and altitudes of the device, which is a known issue (Rieger et al, 2015). It is worth pointing out that the measurements are not performed at exactly the same location.

\section{Conclusions}

In this work we present an approach for retrieving particle size and extinction coefficient profiles of the stratospheric aerosol layer from multi-color measurements with the ALOMAR-RMR lidar in northern Norway. The retrieval approach is based on comparing measured and modelled color ratios of the wavelengths $1064 \mathrm{~nm}$ and $532 \mathrm{~nm}$. In a first retrieval step profiles of the aerosol median radius - assuming a log-normal particle size distribution with fixed width - are obtained. These are used in a second step - together with temperature and density profiles - to calculate the desired aerosol extinction profiles. Although assumptions on the aerosol properties have to be made, the inferred extinction coefficients are relatively robust against variations of the assumed distribution width, which constitutes the dominant error source. Additionally, aerosol density profiles were computed, though with larger uncertainties.

The median radii of the aerosol size distribution obtained with this approach are in good overall agreement with other independent particle size measurements (except those by SAGE II) which confirm that our assumptions are valid. The consequence of a potential low bias in aerosol size is a high bias in aerosol density. In the case of density profiles, however, the broad error ranges should be kept in mind.

Finally, the direct comparison with extinction coefficient profiles obtained by satellite-borne measurements show a significant relative difference of roughly $40 \%$ at altitudes around $20 \mathrm{~km}$ which in case of OSIRIS can reach over $100 \%$ at higher altitudes. As pointed out, this high deviation is 
https://doi.org/10.5194/amt-2019-267

Preprint. Discussion started: 25 July 2019

(c) Author(s) 2019. CC BY 4.0 License.

365 probably caused by a low bias of the aerosol extinction retrieved from OSIRIS measurements at high

366 northern latitudes and the respective altitudes.

367 Code and data availability

368 The datasets used in this study can be obtained by contacting the first author.

369 Competing interests

370 The authors declare that they have no conflict of interest.

371 Author contribution

372 Christian von Savigny and Jacob Zalach developed and implemented the described method whith

373 the help of other authors.

374 Acknowledgements. This work was funded by the Deutsche Forschungsgemeinschaft (DFG, grant SA-1351/7)

375 and supported by University of Greifswald as well as the Leibniz Institute of Atmospheric Physics at Kühlungsborn. 


\section{References}

A. Angström, On the atmospheric transmission of Sun radiation and on dust in the air, Geogr.Ann., 11, 156 $166,1929$.

Baumgarten G., Fiedler J., von Cossart G.: The size of noctilucent cloud particles above ALOMAR (69N,16E): Optical modeling and method description, Advances in Space Research 40, 772-784, doi:10.1016/j.asr.2007.01.018, 2007.

Bingen C., Vanhellemont F., and Fussen D.: A new regularized inversion method for the retrieval of stratospheric aerosol size distributions applied to 16 years of SAGE II data (19842000): method, results and validation, Annales Geophysicae, 21, 797 - 804, 2003.

Bingen, C., Fussen, D., and Vanhellemont, F.: A global climatology of stratospheric aerosol size distribution parameters derived from SAGE II data over the period 1984-2000: 1. Methodology and climatological observations, J. Geophys. Res., 109, D06201, doi:10.1029/2003JD003518, 2004a.

Bingen C., Fussen D., and Vanhellemont F.: A global climatology of stratospheric aerosol size distribution parameters derived from SAGE II data over the period 19842000: 2. Reference data, J. Geophys. Res., 109, D06202, doi:10.1029/2003JD003511, 2004b.

Blum, U., Khosrawi, F., Baumgarten, G., Stebel, K., Müller, R., and Fricke, K. H.: Simultaneous lidar observations of a polar stratospheric cloud on the east and west sides of the scandinavian mountains and microphysical box model calculations, Ann. Geophys., 24, 3267 - 3277, 2006.

Bourassa, A. E., Degenstein, D. A., and Llewellyn, E. J.: Retrieval of stratospheric aerosol size information from OSIRIS limb scattered sunlight spectra, Atmos. Chem. Phys., 8, 6375 - 6380, 2008.

Bourassa A. E., Rieger L. A., Lloyd N. D., and Degenstein D. A.: Odin-OSIRIS stratospheric aerosol data product and SAGE III intercomparison, Atmos. Chem. Phys., 12, 605 - 614, 2012

Brand, A., Baumgarten, G., Fiedler, J., Lübken, F.-J., von Savigny, C., and Zalach, J.: Year-round stratospheric aerosol backscatter ratios calculated from lidar measurements above Northern Norway, submitted to Atmos. Meas. Tech., 2019.

Bucholtz, A., Rayleigh-scattering calculations for the terrestial atmosphere, Appl. Opt., 34(15), 2765 - 2773, 1995.

Crutzen, P. J.: The possible importance of CSO for the sulfate layer of the stratosphere, Geophys. Res. Lett., 3, 73 - 76, doi:10.1029/GL003i002p00073, 1976.

DeLand M., Bhartia P., Xu P., and Zhu T.: OMPS Limb Profiler Aerosol Extinction Product AER675: Version 0.5 Data Release Notes, 2016

Deshler, T.: A review of global stratospheric aerosol: Measurement, importance, life cycle, and local stratospheric aerosol, Atmos. Res., 90, 223 - 232, doi:10.1016/j .atmosres.2008.03.016, 2008.

European Centre for Medium-Range Weather Forecasts (ECMWF), The ERA-Interim reanalysis dataset, Copernicus Climate Change Service (C3S) (accessed January 2019), available from https://apps.ecmwf.int/datasets/data/interim-full-moda/levtype=pl/

Jaross G., Bhartia P.K., Chen G., Kowitt M., Haken M., Chen Z., Xu P., Warner J. and Kelly T.: OMPS Limb Profiler instrument performance assessment, J. Geophys. Res. Atmos. 119, 4399 - 4412, 2014

Jumelet, J., Bekki, S., David, C., and Keckhut, P.: Statistical estimation of stratospheric particle size distribution by combining optical modelling and lidar scattering measurements, Atmos. Chem. Phys., 8, 5435-5448, 

stein D. A., Rieger L. A., Bingen C., Vanhellemont F., Robert C., DeLand M. and Bahartia P.K.: Variability and evolution of the midlatitude stratospheric aerosol budget from 22 years of ground-based lidar and satellite observations, Atmos. Chem. Phys., 17, 1829 - 1845, 2017. Llewellyn, E. J., Lloyd N. D., Degenstein D. A., Gattinger R. L., Petelina S. V., Bourassa A. E., Wiensz J. T., Ivanov E. V., McDade I. C., Solheim B. H., McConnell J. C., Haley C. S., von Savigny C., Sioris C. E., McLinden C. A., Griffioen E., Kaminski J., Evans W. F. J., Puckrin E., Strong K., Wehrle V., Hum R. H., Kendall D. J. W., Matsushita J., Murtagh D. P., Brohede S., Stegman J., Witt G., Barnes G., Payne W. F., Piche L., Smith K., Warshaw G., Deslauniers D. L., Marchand P., Richardson E. H., King R. A., Wevers I., McCreath W., Kyrl E., Oikarinen L., Leppelmeier G. W., Auvinen H., Megie G., Hauchecorne A., Lefevre F., de La Ne J., Ricaud P., Frisk U., Sjoberg F., von Scheele F. and Nordh L.: The OSIRIS instrument on the Odin satellite, Can. J. Phys., 82, 411 422, doi:10.1139/P04-005, 2004. using CPFM polarized limb radiances, J. Atmos. Sci., 56, 233 - 240, 1999. Mie scattering routines, University of Oxford, Departement of Physics, http://eodg.atm.ox.ac.uk/MIE/index.html, last access: 31 December 2018 Murtagh, D., Frisk U., Merino F., Ridal M., Jonsson A., Stegman J., Witt G., Eriksson P., Jimnez C., Megie G., de la Ne J., Ricaud P., Baron P., Pardo J., Hauchcorne A., Llewellyn E. J., Degenstein D. A., Gattinger R. L., LloydN. D., Evans W. F. J., McDade I. C., Haley C. S., Sioris C., von Savigny C., Solheim B. H., McConnell J. C., Strong K., Richardson E. H., Leppelmeier G. W., Kyrl E., Auvinen H. and Oikarinen L.: An overview of the Odin Atmospheric Mission, Can. J. Phys., 80, S1, 309 - 319, 2002. Optics, 14 (1), $208-219,1975$ Rieger L., Bourassa A. and Degenstein D.: Merging the OSIRIS and SAGE II stratospheric aerosol records, J.Geophys. Res. Atmos., 120(17), DOI: 10.1002/2015JD023133 Tie, X. and Brasseur, G.: The response of stratospheric ozone to volcanic eruptions: Sensitivity to atmospheric chlorine loading, Geophys. Res. Lett., 22, 22, 3035 - 3038, 1995. Ugolnikov, O. S. and Maslov, I. A.: Investigations of the Background Stratospheric Aerosol Using Multicolor Wide-Angle Measurements of the Twilight Glow Background, Cosmic Research, 56, 2, 85 - 93, doi:10.1134/S0010952518020119, 2018, Original Russian Text, 2018, published in Kosmicheskie Issledovaniya, 2018, 56, 2, $95-102,2018$. Cossart G., Fiedler, J. and von Zahn, U.: Size distributions of NLC particles as determined from 3-colour 12 observations of NLC by ground-based lidar, Geophys. Res. Lett., 26, 1513 - 1516, 1999. von Zahn, U., von Cossart, G., Fiedler, J., Fricke, K. H., Nelke, G., Baumgarten, G., Rees, D., Hauchecorne, A., and Adolfsen, K.: The ALOMAR Rayleigh/Mie/Raman lidar: objectives, configuration and performance,

453 Yue, G. K. and Deepak A.: Retrieval of stratospheric aerosol size distribution from atmospheric extinction of solar radiation at two wavelengths, Appl. Opt., 22(11), 1639-1645, 1983. 